\title{
Primary School Teachers' Practice and Challenges of School-Based Assessment (SBA) System in Asikuma-Odoben-Brakwa District
}

\author{
Daniel Appiah \\ Department of Arts and Social Sciences Education, University of Cape Coast, Ghana
}

\begin{abstract}
The purpose of this study was to assess primary school teachers' practice and challenges of School-Based Assessment (SBA) system. The study used the descriptive survey design. The cluster and disproportional sampling techniques were used to sample 240 primary school teachers in Asikuma-Odoben-Brakwa District for the study. Self-developed observational check-list and self-developed questionnaire were used for the data collection. Descriptive statistics such as frequencies and percentages, mean of means and standard deviations were used to analyse the data. The study found that to a high extent teachers practice the School-Based Assessment (SBA) using the policy guidelines. Again, the study showed that primary school teachers face challenges such as; unavailability of assessment materials, no expert support to teachers in assessment task preparation and no provision of project topics by the District Education Office. In view of this, the study recommended that Educational Directorates should encourage teachers to follow the laid down procedures in administration of SBA by organizing frequent workshops on the practice of SBA for the teachers.
\end{abstract}

Keywords: school-based assessment, practice, primary school teachers

DOI: $10.7176 / \mathrm{JEP} / 11-4-13$

Publication date: February $29^{\text {th }} 2020$

\section{Introduction}

In Ghana, School-Based Assessment (SBA) is a modified form of continuous assessment (CA) in the school system. This change came as a result of the failure of the CA to make the expected contributions to pupils' school performance (Awoniyi, 2016). The School-Based Assessment has presently reduced the number of assignments to make it easily to be handled by both teachers and students. It is therefore expected that the SBA would help teachers and students to achieve the objectives of the syllabus and consequently raise the standard of learning in the country (Curriculum Research Development Division, 2009). According to Ministry of Education (MOE) (2011), teachers are to administer the classroom assessment task to the learners at the end of every month in a term. Here are the names of the various time modes and class assessment task (CAT's) teachers are to follow in their practice of SBA:

Class assessment task 1 (CAT 1): the first class test, is administered at end of week 4 in the term.

Class assessment task 2 (CAT 2): the group exercise, is administered at end of week 8 in the term.

Class assessment task 3 (CAT 3): the second class test, is administered at end of week 11 in the term.

Class assessment task 4 (CAT 4): the project, is administered at the beginning of the term.

In the implementation of the SBA, teachers need to clearly understand the objectives of the SBA assessment as well as follow strictly the guidelines provided for its implementation. As seen in Figure 1, the extent to which teachers practice the SBA according to the SBA guidelines in the classroom might be negatively or positively influenced by their understanding of the objectives of the SBA and the challenges that are faced in the practise of the SBA system.

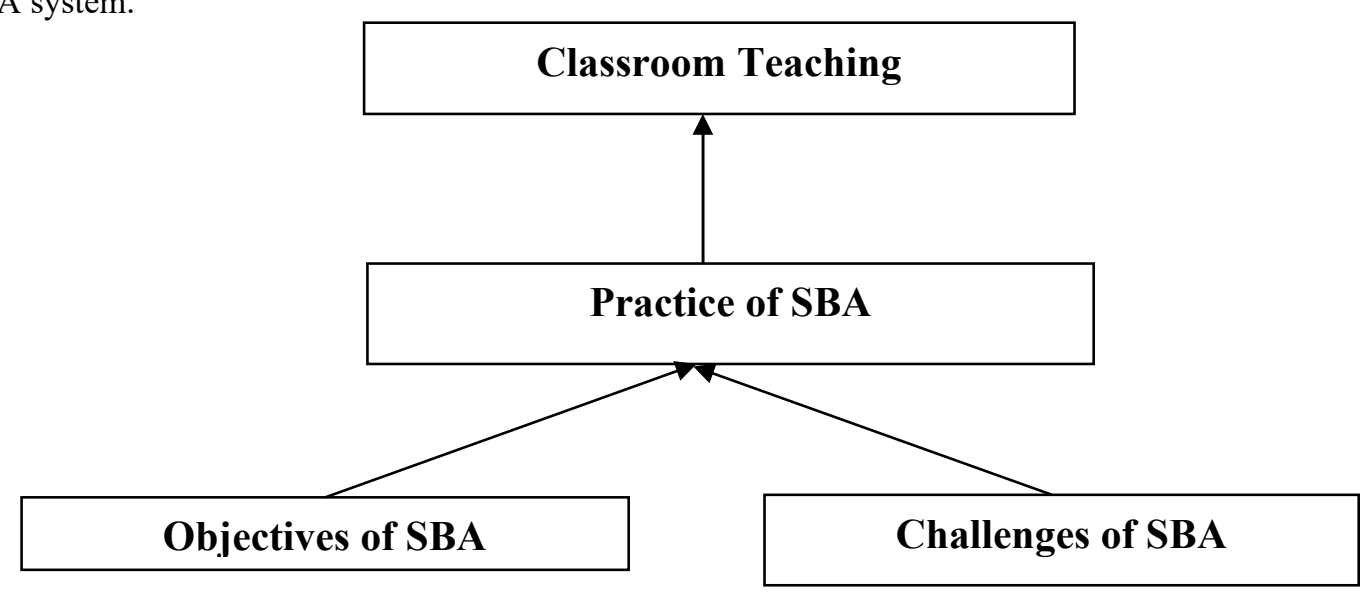

Figure 1: Conceptual Framework (Author's construct, 2020) 
This is to say that if practicing teachers do not understand the objectives of the SBA and are, therefore, not able to achieve them, coupled with the challenges faced in practicing the SBA system, it would limit the degree to which it is practice. In effect, if the SBA is properly practiced by the teachers, then standardisation of assessment practices would be observed in all schools. This would provide an objective comparison of students' academic performances across schools. Again, it might positively influence classroom teaching since teachers would be in the capacity to tell how students might perform academically when they take external examinations which are most often standardised.

It is argued at this point that the successful implementation of the SBA system depends on teachers practise and understanding of the SBA objectives and the availability of resources needed to practise the SBA system. Literature has shown that the successful implementation of any curriculum is hindered if appropriate support materials are not available. This is to say that if resources needed for the practise of the SBA system is absent, the objectives of the SBA system is not likely to be achieved, which might lead to the poor implementation of the SBA system. In effect, teachers might not be in the capacity to improve teaching and learning through the use of the SBA system. This study, therefore sought to assess how teachers are practising the SBA assessment policy in Ghanaian basic schools.

\section{STATEMENT OF THE PROBLEM}

According to 2014 annual report by Deputy Director in charge of supervision in Asikuma-Odoben-Brakwa District Education office, primary school teachers do not practice the SBA system as it is expected. Despite the many aspects of SBA such as teachers' assistance and remediation, standardization of SBA, modes of SBA, SBA times of administration and SBA project work that are practice by the primary school teachers in the classroom, the report failed to indicate the aspects of the SBA that teachers were not practising to expectation. Therefore, this study was conducted to establish the extent to which teachers practice the SBA according to policy guide lines.

\section{Purpose of the Study}

The general purpose of this study was to assess primary school teachers' practice of School-Based Assessment (SBA) system.

\section{Research Questions}

The following research questions were formulated to guide the study.

1. What extent do primary school teachers in Asikuma- Odoben- Brakwa District practise the SchoolBased Assessment system according to the policy guidelines?

2. What challenges do primary school teachers in Asikuma- Odoben- Brakwa District face in practicing the School-Based Assessment system?

\section{RESEARCH METHODOLOGY}

This study adopted descriptive survey design. Gay (1992) asserts that descriptive survey design befits investigations concerning educational problems including evaluation or assessment of attitude, opinions, demographic information, conditions and procedures. The researcher realized that the descriptive survey design is appropriate design for the study of assessment of primary school teachers' practice of School-Based Assessment (SBA) system. This study concerns with assessing issues in the practice of SBA in order to describe the current condition of the practice of School-Based Assessment in the classroom. Another reason for the adoption of the descriptive survey design is that, it is suitable for either a quantitative or qualitative research where there is the formulation of hypotheses or research questions to be tested or answered in order to describe situations (Cohen, Manion \& Morrison, 2003).

The population for this study was all the public primary school teachers in 98 public primary schools in Asikuma -Odoben - Brakwa District. They were totaled 588 in number. This data was obtained from AsikumaOdoben-Brakwa District Educational Directorate in 2016. The population was made up of males and females, for which $95 \%$ have professional certificate in teaching as professional teachers. A sample size of 240 was used for this study. This was made up of teachers from all the eight (8) cluster of schools within the district. Ogah (2013) in a sample size determination table explains that a proportional sample size of (235) could be selected from a population of 600 for a study. Therefore, a sample of 240 increased the external validity of the study. The sampling procedures adopted for the study were the cluster and disproportion sampling technique. The justification for using these sampling procedures was to enable the researcher to get a fair representation of schools and teachers in different geographical locations within the district in the study. The data collection instruments used for this study were questionnaire and observational checklist for document analysis.

In order to ascertain the content related evidence of validity of the instruments, expert opinion was sought from supervisors, lecturers, and some course mates who had taught and practiced SBA assessment in primary schools before enrolling on the Master of Philosophy programme. This consultation was done for both the questionnaire and the observational checklist. Again, the instruments were pre-tested in ten (10) purposely 
selected public primary schools in Ajumako-Enyan-Essiam District in the Central region of Ghana. All the teachers in the selected schools totaling sixty were used. The pre-test findings showed no significant errors in the instrument.

\section{Results and Discussion}

The data gathered for the research questions one was analysed using mean and standard deviation and content analysis. The data for research question 2, 3 and 4 were analysed by mean and standard deviation. The mean of means of the items above 2.5 were considered above the average (respondents agreed or often practice the statement provided) while mean of means of the items below 2.5 were considered below the average (respondents do not agreed or not often practice the statement provided).

\section{Demographic Characteristics of the Respondents}

The demographic characteristics of the teachers which were considered include: gender, highest academic qualification and highest professional qualification. These demographic information enriched the understanding about the category of respondents who were involved in the study. The background information of the respondents which were considered in the study is presented in Table 2 .

Table 2: Socio-Demographic Information of the Respondents

\begin{tabular}{llll}
\hline Variable & Sub-Scale & $\mathrm{N}$ & $\%$ \\
\hline Gender & Male & 102 & 42.5 \\
& Female & 138 & 57.5 \\
Highest Academic Qualification & Diploma & 140 & 58.3 \\
& First Degree & 83 & 34.6 \\
& SSCE/WASSCE & 13 & 5.4 \\
& Master's Degree & 2 & .8 \\
Highest Professional Qualification & CTC III & 2 & .8 \\
& Diploma in Basic Education & 135 & 56.3 \\
& Bachelor's Degree in Education & 93 & 38.8 \\
& 3- Year Post Sec Cert “A" & 1 & .4 \\
& M. Ed. Degree & 1 & .4 \\
\hline
\end{tabular}

Source: Field Data, (2020)

Regarding the gender of the teachers who participated in the study, the data in Table 2 shows that 138 $(57.5 \%)$ were females while $102(42.5 \%)$ were males. This shows clearly that there were more female respondents than male respondents for the study. This wouldn't affect the outcome of the study since all the respondents have had training on the practice of SBA.

It is also seen from Table 3 that the majority, 140 (58.3\%), of the respondents had Diploma Degrees while $83(34.6 \%)$ had First Degrees and $13(5.4 \%)$ had WASSCE or SSCE's. It could also be seen that the least $2(.8 \%)$ respondents had their Master's Degrees and $2(.8 \%)$ also have Construction Technician Certificate (CTC) III. This means that majority of the teachers who participated in the study possessed the appropriate certificates that qualifies them as teachers in the basic school. This makes the respondents ideal for this study since they have had training as teachers.

It is evident from Table 3 that majority, 135 representing $56.3 \%$ of the respondents had Diploma in Basic Education as their Highest Professional Qualification and 93 representing 38.8\% had Bachelor's Degree in Education as Highest Professional Qualification. From Table 3 it can also be seen that only one (.4\%) had a 3year Post Secondary Certificate "A" as the Highest Professional Qualification while one (.4\%) also had Master of Education Degree as Highest Professional Qualification. Also 10 respondents representing 4.2\% had no Professional Qualification. This shows that majority of the respondents had professional qualification. By implication, the respondents may have adequate knowledge on the practice of SBA that the study sought to assess. They are, therefore, expected to bring their expertise to their teaching in the classroom.

Research Question One: What Extent do Primary School Teachers Practice the School-Based Assessment according to the Policy Guidelines?

The intent of this research question was to determine the extent to which primary school teachers practice SBA in accordance with the policy guidelines formulated by the Curriculum Research and Development Division (CRDD) unit of the Ghana Education Service. Data on this research question one is presented in Table 2. 
Table 2: The Extent to which Teachers Practice SBA

\begin{tabular}{|c|c|c|}
\hline Statement & Mean & SD \\
\hline $\begin{array}{l}\text { I administer Classroom Assessment Task one (CAT 1) at the end of the first four weeks of a } \\
\text { term }\end{array}$ & 2.85 & .89 \\
\hline $\begin{array}{l}\text { I administer Classroom Assessment Task two (CAT 2) at the end of the seventh week of a } \\
\text { term }\end{array}$ & 2.54 & .85 \\
\hline I administer CAT 1 as individual test & 2.87 & 1.01 \\
\hline I administer CAT 2 as a group exercise & 2.49 & .96 \\
\hline I give project work to my pupils at the beginning of every term & 2.21 & .94 \\
\hline I collect my project work at the end of every term & 2.36 & 1.05 \\
\hline I administer CAT 2 as individual exercise & 2.55 & 1.00 \\
\hline I give project work to my pupils once in the academic year & 2.26 & .99 \\
\hline I administer CAT 2 at the end of the eighth week of a term & 2.53 & .92 \\
\hline I administer CAT 3 at the end of the twelfth week of the term & 2.36 & 1.00 \\
\hline I administer CAT 4 as a project work & 2.47 & 1.02 \\
\hline I administer CAT 3 as both written and objective test & 2.87 & .95 \\
\hline I add the SBA scores to the end of term examination scores & 3.27 & .96 \\
\hline I conduct four (4) classroom assessment tasks (CATS) in a term & 2.77 & 1.02 \\
\hline I give exercise to my pupils at the end of every lesson taught & 3.39 & .86 \\
\hline Mean of Means/ Average Standard Deviation & 2.65 & .96 \\
\hline
\end{tabular}

Source: Field Data, (2020)

With the item, "I give exercise to my pupils at the end of every lesson taught", it can be seen from Table 4 that majority, $($ Mean $=3.39$, Standard Deviation $=.86)$ of the teachers sampled for the study indicated that they give exercise to pupils at the end of every lesson taught and this is an above average performance. This means that the teachers sampled for the study comply with that aspect of the SBA, thus, practice as it is expected. Teaching and learning is expected to be improved day by day and classroom assessment seems to play a critical role in improving instruction. According to the Ministry of Education (2011), class exercise is one of the different test modes SBA requires classroom teachers to use for assessing pupils academic performance. It can be inferred, therefore, that the sampled teachers comply with the provision of the SBA that specifies that, classroom exercises should be used to assess the pupils based on the objectives of the lessons taught. This practice if well carried out by teachers should place them in the position to easily identify the strengths and weaknesses of the students in order to enhance classroom instruction. Therefore, the sampled teachers need to be encouraged to continue such practice constantly.

Again, in response to the statement, "I add the SBA scores to the end of term examination scores", it was discovered from the data in Table 4 that the sampled teachers, $($ Mean $=3.27$, Standard Deviation $=.96)$ were of the view that they add the SBA scores to the end of term examination scores and their practice was above average. This shows that pupils' true academic performance is recorded over the period of study by the use of classroom assessment as desired by the SBA system. By implication, the teachers sampled for the study comply with this aspect of the SBA that ensures that classroom assessment scores obtained by a pupil reflect the true ability of the pupil in the external examination such as the Basic Education Certificate Examination (BECE).

From Table 4, response to the statement "I administer Classroom Assessment Task 1 as individual test", revealed that the teachers sampled for the study administer Classroom Assessment Task 1 as individual test. This was practiced with a mean of 2.87 and Standard deviation 1.01, which is above average and their response was in line with the demands of the SBA. According to Ministry of Education Teacher's Hand Book on SBA (2011), teachers are expected to conduct Classroom Assessment Task 1 as individual class test. This is important since it will enable classroom teachers to determine the progress individual pupils are making in the learning process. Again, it can also help the teachers to identify individual differences among their pupils in terms of their academic achievement. The individual CAT scores can inform the classroom teachers on the best strategies to adopt to help the pupil to maximize their academic performance. This implies that teachers should be encouraged to practice this aspect of the SBA with all seriousness.

In another vein, when the statement "I administer CAT 2 at the end of the eighth week of the term" was put, the data in Table 4 shows that the respondents of the study administer CAT 2 at the end of the eighth week of the term. Their practices $($ Mean $=2.53$, Standard Deviation $=.92)$ of this item of the SBA was above average. This shows that the sampled teachers for the study comply with that aspect of SBA which requires that CAT 2 should be administered at the end of the eighth week of the term. This ensures collection of assessment information on pupil's academic performance on interval basis. Again, it could help the teachers to organize a remediation instruction for pupils who would show weak ability in their academic performance.

The mean of means (2.65) indicates that the sampled teachers' practice of SBA is above average (high extent). The average standard deviation (.96) also indicates overall homogeneity in the responses of the 
respondents. Therefore, the overall indication was that to a high extent the sampled teachers often practice SBA according to the policy guideline. This finding in the area of contextual evaluation contradicts the views of Nugba (2012) who found out that Junior High School core subject teachers implementation of the SBA does not follow the SBA policy guidelines. Similarly, the finding go contrary to Awoniyi (2016) who also found out that Senior High School mathematics teachers do not practice the SBA according to the policy guideline. Kapambwe (2010) who also found that Zambia teachers find it difficult to suddenly change from predominated use of CA to the School-based assessment.

In order to confirm the responses on the extent to which primary school teachers practice SBA according to the policy guidelines, a structured observational checklist was administered to check the various documents on SBA from the sampled schools whose teachers were used as respondents in the study. The observation was done in the third term to enable the researcher to observe SBA activities in one academic year. Qualitative method was employed to do documentary analysis on the assessment records that were observed in the schools.

The first document that was observed in each of the schools was the "SBA record sheet". The SBA record sheet contains the marks allocation for the various component and modes of the SBA such as CAT 1, CAT 2, CAT 3 and Projects. Therefore, a teacher is expected to enter the marks a pupil will obtain in the various class test and group exercises on the record sheet after every SBA administration.

Out of the 40 sampled schools used for the study, it was discovered that twenty five (25) head teachers were having the SBA record sheet kept in the schools office. While the head teachers of the fifteen (15) sampled schools were not having the record sheet in their schools. This made it difficult for the researcher to confirm the responses on some of the aspect of the SBA in these fifteen schools. Therefore, the researcher observed other document such as pupils' exercise books, copy of class test questions and copies of project topics in addition to the record sheet to confirm responses in all the schools.

It was discovered from the record sheet that, the teachers had recorded the results of the CAT 1 assessment that was administered at the end of the first four weeks of the term. This means that the essence of the new assessment system had been well appreciated by the teachers. CAT 1 as indicated earlier was administered as individual task undertaken by the pupils. This confirms the responses on the questionnaire that the sampled teacher practice of CAT 1 is above average. It was discovered from the record sheet that few teachers in all the schools entered the marks for the CAT 2 on the record sheet. This confirms the earlier assertion that the time for CAT 2 administration was not comply with. From the record sheet it was discovered that most of the teachers had recorded the pupils' marks for the CAT 3 indicating that teachers administered the CAT 3 on the eleventh week. This shows that the sampled teachers administer the CAT3 to the best of their abilities since it could inform them about how the pupils are prepared for the end of the term examination. This observation also confirms what the sampled teachers indicated on the questionnaire.

Based on the findings from the document analysis, it could be said that the sampled teachers administered CAT 1, CAT 2 and CAT 3 on the exact time modes stated in the SBA guideline. Again, it was realised that the sampled teachers administered CAT1, CAT 2 and CAT 3 as individual class test, group exercises and individual class test respectively.

What Challenges do Primary School Teachers Face in Practising the School-Based Assessment System? The third research question sought to find out the challenges that hinder the successful practice of the SBA system. Data on the challenges primary school teachers face in practicing the SBA are presented in Table 6.

\section{Table 6: Challenges Teachers face in the Practice of SBA System}

\begin{tabular}{lll}
\hline Statement & Mean & SD \\
\hline I do not get support from expert(s) for the preparation of assessment items & 2.95 & 1.02 \\
Printing materials for assessing students are not available in my school & 2.90 & 1.07 \\
The project topics for assessing the students are not provided by the District Education Office & 2.95 & 1.01 \\
The SBA workload makes it difficult for me to mark my pupils work after conducting the SBA & 2.49 & 1.01 \\
I consider school-based assessment to be more time consuming & 2.73 & .90 \\
I don't have records keeping equipment (eg. Computer) of SBA in my school & 2.84 & 1.08 \\
I do not have SBA converted score sheet in my school & 2.70 & 1.08 \\
Mean of Means/Average Standard Deviation & 2.80 & 1.08 \\
\hline
\end{tabular}

Source: Field Data, (2020)

Response to the statement "the project topics for assessing the students are not provided by the District Education Directorate", shows that the majority, (Mean $=2.95$, Standard Deviation $=1.01$ ) of the teachers sampled for the study affirmed that the project topics for assessing the students are not provided by the District Education Office, for which their affirmation was above average performance. In other words, the sampled teachers were not supplied with the project topics that should be administered to the pupils at the beginning of the term from District Education Office. According to CRDD, projects topics should consist of investigations, experiments and material production in the subject of study. The topics should compel the pupils to use highorder abilities such as analysis, evaluation, self-correction and synthesis of ideas and should be provided by the 
District Education Directorates (Quansah, 2005). The refusal of the District Education Officers to provide the appropriate project topics could go a long way to defect the standardization of the practice of the teachers in different schools.

With the statement "I do not get support from expert(s) for the preparation of assessment items", the data in Table 6 shows that majority, (Mean $=2.95$, Standard Deviation $=1.02)$ of the sampled teachers agreed that the necessary support needed in the preparation of assessment items are not given to them by the experts in the field and their agreement to the statement was above average. This is one of the major challenges experience by practicing teachers in the classroom. The issue of effective curriculum implementation seems to rely on support materials needed to realise the objective of the curriculum. Most teachers seem not to fully implement the curriculum due to challenges they face regarding the form of support needed. Curriculum support has been realized to be critical if any mark should be achieved in the educational sector. If teachers are complaining that they do not get the needed help to prepare assessment items, then it is likely that they might get to a point where they would prepare defective assessment tasks. It's no doubt many schools now rely on purchased test items from private organisations.

In addition, when the sampled teachers were asked "Printing materials for assessing students are not available in my school", the majority of the teachers, (Mean $=2.90$, Standard Deviation $=1.07)$ asserted that printing materials for assessing students are not available in the schools. Their agreement to the statement was above average. The unavailability of computer, printers, printing papers and photocopy machine in the schools would mean that the head teachers and teachers would have to spend more money to print SBA questions for pupils and so where there is no money in the account of the school, then teachers would not be able to practice SBA. This could limit the number of assessment tasks the teachers might allow their students to undertake. This is likely to cause the teachers to compromise on quality and the number of assessment tasks needed to ensure a complete evaluation of the academic performance of the students. In effect, the ability of teachers to fully comply with the demands of SBA could be jeopardized.

Again, the respondents were questioned by the statement "I consider School-Based Assessment to be more time consuming", in the same vein, majority, (Mean $=2.73$, Standard Deviation $=.90)$ of the sampled teachers indicated that the SBA was more time consuming, for which their level of agreement was above average. It is believed that the SBA has come to reduce the assessment demands on teachers by almost 64\% (CRDD, 2011). However, it seems the teachers did not 'absolutely' recognise that assertion since the majority of them saw it to be time consuming. It is not surprising that the teachers earlier on indicated that they needed support to carry out the mandate of the SBA system. This is quite laudable because the teachers had to entirely implement a new assessment system which they were not used to.

Again, the sampled teachers' indication to the statement "I don't have records keeping equipment (eg. Computer) of SBA in my school", in Table 6 shows that the majority, (Mean $=2.84$, Standard Deviation $=1.08$ ) of the sampled teachers were of the view that there were no record keeping equipment (eg. computer) in their schools and their agreement to the statement was above average.

It can be said, the sampled teachers face a number of challenges in practicing the SBA system according to the policy guideline in order to ensure standardisation of assessment practices. The notable challenges were that assessment materials were unavailable, there was no support given to the teachers in preparing assessment tasks, project topics were not provided by the District Education Office and time consuming nature of SBA made the assessment more difficult.

\section{SUMMARY, CONCLUSION AND RECOMMENDATION}

The study found that teachers administered the various assessment tasks (CAT 1, CAT 2 and CAT 3) on the exact time modes stated in the SBA guideline. Again, it was also seen that the sampled teachers administered CAT1, CAT 2 and CAT 3 as individual class test, group exercises and individual class test respectively. In addition, it was found that the sampled teachers recorded the marks pupils obtained from SBA exercises in the SBA recording sheet in the schools.

Again, the study found that the sampled teachers face challenges such as; unavailability of assessment materials, lack of support by expert to teachers when preparing assessment tasks and lack of project topics. The study revealed that some of the sampled teachers were not given project work to their pupils in some of the schools.

\section{CONCLUSIONS}

Based on the findings of the study the following conclusions have been made. The study found that the majority of the sampled teachers practice SBA according to the policy guidelines and this would ensure pupil-centred learning that could implant high ability thinking skills in the pupils. Again, problems that lead to low performance of students on national tests caused by teacher-centred approach used in the instructional system in schools could be eliminated. This notwithstanding teachers face challenges such as; unavailability of assessment 
materials, lack of support by expert to teachers when preparing assessment tasks, lack of project topics to be administered to pupils resulting from the failure of District Education Offices to provide them and the time consuming nature of the SBA made the practice difficult. These identified challenges could jeopardise the purpose and aims of the SBA as well as making its practice difficult.

In view of the findings resulting from the study and conclusions drawn based on the findings, the following recommendations are made for the improvement of the practice of School-Based Assessment;

1. In order to sustain the primary school teachers' quest for good practice of the SBA according to the policy guidelines, it is recommended that Ministry of Education and Educational Directorates organize periodic workshops on the SBA practice to primary teachers, especially, newly recruited teachers who join the teaching service.

2. Heads of Schools, Educational directorates, Parent Teachers Association, School Management Committee and all other educational stakeholders should provide resources such as; SBA manuals, Assessment hand books, computers and record keeping equipment to the schools to aid challenge free for SBA practice. Besides, Educational directorates should provide the SBA project topics for the schools as it enshrined in the SBA policy.

\section{References}

Awoniyi, F. C. (2016). The understanding of senior high school mathematics teachers of School-Based Assessment and its challenges in the Cape Coast Metropolis. British Journal of Education, 4(10), 22-38.

Cohen, L., Manion, L., \& Morrison, K. (2003). Research methods in education. New York: Routledge/Falmer.

Curriculum Research and Development Division [CRDD] (2009). Teaching syllabus for Junior high school mathematics. Accra: Ghana Publishing Corporation.

Gay, R. L. (1992). Educational research: Competencies for analysis and application. (4th ed.). New York: Macmillan Publishing Company.

Kapambwe, W. M. (2010). A formative evaluation of the implementation of the continuous assessment pilot programme (CAPP) at the basic school level in Zambia. Unpublished master's thesis, University College Dublin, Dublin.

Quanasah, K. B. (2005). Continuous assessment handbook. Accra: BECAS Project Publication.

Ministry of Education (2011). Teachers' handbook on school-based assessment for upper primary six. Accra. Ghana Publishing Corporation.

Nugba, R. (2012). An evaluation of the implementation of school-based assessment in the junior high schools in the Obuase Municipality in the Ashanti Region of Ghana. Unpublished master's thesis, University of Cape Coast, Ghana.

Ogah, J. K. (2013). Decision making in the research process. Accra: Adwinsa Publications Ltd. 